Education and Research Hospital, Antalya, Turkey; ${ }^{14}$ Ottawa University, Ottawa, Canada

Background: Methotrexate (MTX) is the most common first-line disease-modified anti-rheumatic drugs in psoriatic arthritis (PsA), despite the controversies. Objectives: In this study, we aimed to determine the rate of withdrawal rate of MTX in PsA and reasons for discontinuing.

Objectives: In this study, we aimed to determine the rate of withdrawal rate of MTX in PsA and reasons for discontinuing.

Methods: A large prospective international multicenter PsA registry was used for this study. Data were collected either at enrolment, based on history, or prospectively if there was a follow up. We analyzed the frequency of MTX usage, discontinuation and the reason for discontinuation. The time on MTX was compared according to the reason of discontinuation (inefficacy vs side effects) using Kaplan-Meier and Cox regression analyses to identify risk factors for discontinuation.

Results: At the time of analyses, 1670 patients had been recruited to the registry and 1359 PsA patients had used MTX during the course of the disease (81.3\%). Within these, $942(69.3 \%)$ were still on MTX at the time of analysis, and 417 (30.7\%) patients have discontinued (Table). The most common reasons for withdrawal were side effects $(219 / 417,52.5 \%)$ and ineffectiveness $(88 / 417,21.1 \%)$. Other reasons included pregnancy, remission, self-decision (11.9\% for all). For 60 patients $(14.3 \%)$, the reason could not be identified. In patients who were still on MTX, the median duration of MTX therapy was 31 months $(I Q R=59)$ compared to 17 months $(I Q R=43)$ in the withdrawal group. The most common side effects were gastrointestinal symptoms (47\%) and abnormal liver function tests (25\%). There was a significant difference in survival plots (Log-rank $p=0.026$ ) with discontinuing due to side effects occurring earlier than inefficacy (Figure 1). In cox regression model, longer disease duration was found as an independent predictor of MTX discontinuation due to all reasons [Hazard Ratio $(H R)=1.01$, 95\% Confidence interval $(\mathrm{Cl})=1.0-1.02 ; \mathrm{p}=0.003$.

Conclusion: MTX is frequently used on PSA treatment, despite the controversies in the literature. One third of patients with PsA discontinue MTX, most commonly due to side effects or inefficacy. Patients discontinue MTX earlier in case of having side effects. Longer disease duration is linked to MTX discontinuation.

Table. Demographics and disease characteristics of study groups

\begin{tabular}{lcccc}
\hline & $\begin{array}{c}\text { All patients } \\
\mathbf{n}=\mathbf{1 3 5 9}\end{array}$ & $\begin{array}{c}\text { Still on MTX } \\
\mathbf{n}=\mathbf{9 4 2}\end{array}$ & $\begin{array}{c}\text { Withdrawal MTX } \\
\text { any reason } \\
\mathbf{n}=\mathbf{4 1 7}\end{array}$ & $\mathbf{p}$ \\
& & & $47.7(14.0)$ & $\mathbf{0 . 0 3 8}$ \\
& $46.4(13.4)$ & $46.1(13.4)$ & $463(39.1)$ & 0.761 \\
Age, mean (SD) & $523(38.5)$ & $360(38.2)$ & $179 / 397(45.1)$ & 0.966 \\
Male gender, n (\%) & $569 / 1258$ & $390 / 861(45.3)$ & & \\
Ever smoking, n (\%) & $(46.2)$ & & $16.4(12.7)$ & $\mathbf{0 . 0 0 3}$ \\
& $14.2(11.7)$ & $14.0(11.2)$ & & \\
Psoriasis duration (years), mean & & & & \\
(SD) & $657 / 1343$ & $471 / 931(50.6)$ & $186 / 412(45.1)$ & 0.066 \\
Polyarthritis, n (\%) & $(48.9)$ & & & \\
& $388 / 1343$ & $267 / 931(28.7)$ & $121 / 412(29.4)$ & 0.797 \\
Axial disease, n (\%) & $(28.9)$ & & & \\
& $644(47.8)$ & $435(46.6)$ & $209(50.5)$ & 0.191 \\
Nail involvement (ever), n (\%) & $1.5(2.6)$ & $1.4(2.6)$ & $2.0(3.2)$ & $<0.001$ \\
Swollen Joint Count, mean (SD) & $3.0(4.4)$ & $3.5(5.0)$ & $4.2(5.4)$ & $<0.001$ \\
Tender Joint Count, mean (SD) & $0.6(0.6)$ & $0.7(0.7)$ & $0.8(0.7)$ & $\mathbf{0 . 0 3 5}$ \\
HAQ, mean (SD) & $37(22)$ & $39(23)$ & $46(25)$ & $\mathbf{0 . 0 0 1}$ \\
BASDAl,mean (SD) & & & &
\end{tabular}

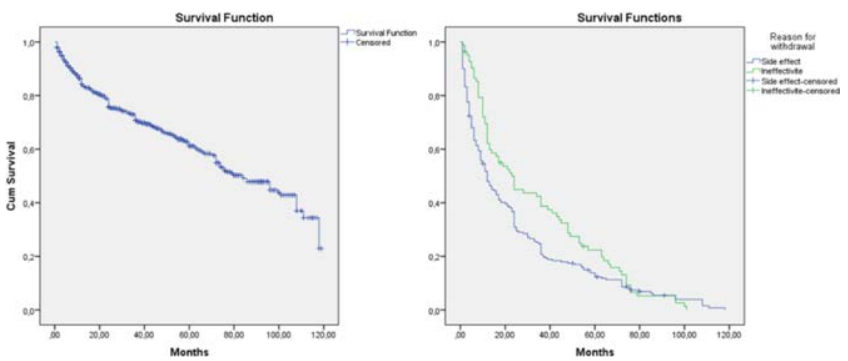

Disclosure of Interests: Dilek Solmaz: None declared, Umut Kalyoncu Consultant of: Abbvie, Amgen, Janssen, Lilly, Novartis, UCB, Ilaria Tinazzi: None declared, Ozun Bayindir: None declared, Ediz Dalkılıç: None declared, Atalay Dogru: None declared, Cem Özișler: None declared, Gezmiş Kimyon: None declared, Gozde Yildirim Cetin Speakers bureau: AbbVie, Novartis, Pfizer, Roche, UCB, MSD, Ahmet Omma: None declared, Emine Figen Tarhan: None declared, Levent Kılıç: None declared, Servet Akar: None declared, Sema Yılmaz: None declared, Meryem Can: None declared, Sule Yavuz: None declared, Orhan Küçükşahin: None declared, Sibel Bakırcı: None declared, Sibel Aydin: None declared

DOI: 10.1136/annrheumdis-2020-eular.2710

\section{SAT0441 BODY COMPOSITION AND FAT DISTRIBUTION IN PATIENTS WITH PSORIASIS OR PSORIATIC ARTHRITIS.}

E. Toussirot ${ }^{1}$, F. Aubin ${ }^{2}$, M. Desmarets ${ }^{1}$, D. Wendling ${ }^{3}$, B. Auge ${ }^{4}$, J. Gillard $^{5}$, O. Messica $^{6}$, X. Guillot ${ }^{3}$, C. Laheurte ${ }^{7}$, E. Monnet ${ }^{8}$, G. Dumoulin ${ }^{9} .{ }^{1}$ University Hospital of Besançon, INSERM CIC-1431, Besancon, France ${ }^{2}$ University Hospital of Besançon, Dermatology, Besancon, France; ${ }^{3}$ University Hospital of Besançon, Rheumatology, Besancon, France; ${ }^{4}$ Private Office, Rheumatology, Besancon, France; ${ }^{5}$ Centre Hospitalier Jura Sud, Rheumatology, Lons le Saunier, France; ${ }^{6} \mathrm{GH}$ Haute Saône, Rheumatology, Vesoul, France; ${ }^{7}$ EFS Bourgogne Franche Comte, Biomonitoring Plateform, Besancon, France; ${ }^{8}$ University Hospital of Besançon, INSERM CIC-1431, Besancon, France; ${ }^{9}$ University Hospital of Besançon, Biochemistry, Besancon, France

Background: Obesity is a leading comorbidity in both psoriasis (Pso) and psoriatic arthritis (PsA) and is associated with common metabolic complications and increased cardiovascular (CV) risk. Obesity is also a risk factor for the onset of these diseases. Body composition and fat distribution have been rarely evaluated in Pso and PsA.

Objectives: In this study, we aimed to characterize the fat mass distribution in patients with Pso or PsA compared to a control group, with a special emphasis on the android/visceral region.

Methods: case-control study (NCT02849795). Patients with Pso (plaque psoriasis) or PSA (CASPAR criteria) were evaluated. Each patient was paired to a control subject, recruited in the same outpatient population, and matched for sex age and body mass index (BMI) category. Clinical assessment included BMI anthropometric measurements (waist circumference, waist /hip ratio), disease activity (PASI for Pso, CPDAI for PsA) and the SCORE CV risk score. Laboratory parameters of inflammation (ESR, CRP, IL-6), lipid parameters (total cholesterol, LDL and HDL cholesterol, triglycerides), metabolic parameters (glycemia, insulin, HOMA), serum adipokines (total and high molecular weight [HMW] adiponectin, leptin, resistin and retinol binding protein 4 [RBP4]) were measured. Body composition (lean mass, fat mass) and fat distribution (android/gynoid regions and visceral fat) were evaluated (DEXA, Lunar GE, CoreScan). Our primary criteria was the fat mass in the android/visceral region. Comparisons between patients and controls were performed with paired $t$ tests, between all groups with ANCOVA (adjusted for age, sex, and BMI category) and Tukey post-hoc tests. Pearson correlations between $\mathrm{CV}$ risk and fat mass were calculated within groups.

Results: 52 patients with Pso and 52 patients with PsA and their respective paired-control were evaluated. Total fat mass was increased in Pso but not in PsA. Android fat and visceral fat were found higher in Pso $(p<0.05)$ while the fat mass measurements did not differ between the patients with PsA and their controls. Waist circumference was higher in patients with Pso compared to their controls. Leptin, leptin/fat mass ratio, and total adiponectin were elevated in PsA while only the HMW/total adiponectin ratio was decreased in Pso. Insulin levels and HOMA were increased in both Pso and PsA groups. Finally, RBP4 was higher in both Pso and PsA patients compared to their respective controls. In patients with Pso, android and visceral fat were correlated with SCORE $(r=0.3$, $p=0.02$ and $r=0.6, p<0.0001$ respectively). In ANCOVA analysis, visceral fat was higher in Pso patients $(p=0.0029)$, with a trend toward higher android fat $(p=0.055)$, compared to PsA patients.

Conclusion: visceral fat is increased in patients with Pso but not in PsA. In parallel, both groups showed an elevation of circulating RBP4. Patients with Pso and PsA were also characterized by metabolic disturbances as showed by the increase in HOMA, and specific adipokine changes. In the Pso group, visceral fat is associated with CV risk evaluated by SCORE. Weight control and reduction of fat mass, especially visceral fat mass, may thus be an important concern in patients with Pso and appears less relevant in PsA.

Disclosure of Interests: None declared DOI: 10.1136/annrheumdis-2020-eular.2611

\section{SAT0442 \\ EVOLVEMENT OF SWOLLEN JOINTS IN THE FIRST YEAR OF EARLY PSORIATIC OLIGOARTHRITIS.}

M. Vis ${ }^{1}, \mathrm{~K}$ Marc $^{2}$, I. Tchetverikov ${ }^{3}$, J. Hazes ${ }^{1}$, J. Luime ${ }^{1}$ on behalf of CICERO. ${ }^{1}$ Erasmus MC, Rheumatology, Rotterdam, Netherlands; ${ }^{2}$ Maasstad Hospital, Rheumatology, Rotterdam, Netherlands; ${ }^{3}$ Albert Schweitzer Hospital, Rheumatology, Dordrecht, Netherlands 
Background: Oligoarthritis and polyarthritis are the predominant phenotypes in PsA. Previous we have shown that patients with oligoarthritis suffer a similar loss in quality of life as polyarthritis patients. ${ }^{1}$ Although oligoarthritis is one of the most prevalent form, ample data is available on this phenotype..$^{2-5}$

Objectives: To evaluate the evolution of swollen joint count over the first year since diagnosis and to assess baseline difference in those groups that evolved differently over time.

Methods: Our study is embedded in the Dutch south-west Early Psoriatic Arthritis (DEPAR) prospective cohort study. We described patient characteristics using simple descriptive analysis techniques. For the comparison across groups univariable multinomial logistic regression was used in STATA15. Oligoarticular disease was defined as 2, 3 or 4 swollen joints,

Results: 175 patients had a complete 12-month evaluation as of February 2019 ( $80 \%$ of all included patients with oligoarthritis). Baseline characteristics are shown in table 1. In total 63 percent of the patients (111/175) had resolution of swollen joints at 1 year. (figure 1). Over the first year, 27 patients had consistently no swollen joints since their 3 month evaluation, 26 had no swollen joint from 6 months and 12 from 9 months and 11 at 12 months. 65 of the $175(37 \%)$ had inconsistently no swollen joints (intermittent) during the first year. In $8 \%$ of the patients values were missing to determine to which group they belonged. Univariable multinomial logistic regression of baseline characteristics showed that the group that had resolution of swollen joints 'early' (within 6 months) compared to (i) the group that 'never' had resolution differed in having fewer tender joints; (ii) the group having 'late' resolution of swollen joints (after 6 months) showed little difference and;(iii) the 'intermittent' group varied in smoking status, fatigue, being female and age. Multivariable analysis may reveal other patterns, but requires a larger sample than that currently available.

Table 1. Baseline characteristics of oligo arthritis patients with complete follow-up at 1 year.

\begin{tabular}{lc}
\hline $\mathbf{n}=$ & 175 \\
\hline sex (\% female) & $45 \%$ \\
age & $51(39-61)$ \\
symptom duration (months) & 10.0 \\
BMI & $28(24-32)$ \\
current smoking & $23 \%$ \\
paid employement & $70 \%(\mathrm{n}=136)$ \\
tender joint count & $3.0(2.0-7.0)$ \\
PASI & $2.0(0.4-4.5)$ \\
entheses & $44 \%$ \\
dactylitis & $9 \%$ \\
VASglobal & $42(21-65)$ \\
VASpain & $49(25-68)$ \\
HAQ & $0.63(0.25-1.13)$ \\
fatigue (BRAF) & $18(10-30)$ \\
\hline
\end{tabular}

\begin{tabular}{|c|c|c|c|c|}
\hline \multirow[b]{2}{*}{3 months } & \multirow[b]{2}{*}{6 months } & \multirow[b]{2}{*}{9 months } & \multicolumn{2}{|c|}{12 months } \\
\hline & & & 0 & sjc! $=0$ \\
\hline \multirow[t]{8}{*}{0} & 0 & 0 & ○ & • \\
\hline & & $s j c !=0$ & • & $\bullet$ \\
\hline & & $\mathrm{mv}$ & - & . \\
\hline & $s j c !=0$ & 0 & $\bullet$ & • \\
\hline & & $\mathrm{sjcl}=0$ & - & - \\
\hline & $\mathrm{mv}$ & 0 & - & \\
\hline & & $s j c !=0$ & . & \\
\hline & & $\mathrm{mv}$ & & . \\
\hline \multirow[t]{7}{*}{ sjc! $=0$} & 0 & 0 & ○ & $\bullet$ \\
\hline & & $s j c !=0$ & $\bullet$ & $\bullet$ \\
\hline & & $\mathrm{mv}$ & . & \\
\hline & $s j c l=0$ & 0 & $\bullet$ & $\bullet$ \\
\hline & & $s j c !=0$ & $\bullet$ & - \\
\hline & & $\mathrm{mv}$ & - & \\
\hline & $\mathrm{mv}$ & $s j c l=0$ & & . \\
\hline $\mathrm{mv}$ & $\mathrm{mv}$ & $s j c !=0$ & & . \\
\hline
\end{tabular}

Figure 1. Evolution of swollen joint count in psoriatic oligo arthritis $(n=175)$ over time expressed in a binary swollen joint count (yes: 0 / no: $s j c !==0 ; m v=$ missing value),

Conclusion: In our set of real world data, about one third of the PsA patients with oligoarticular disease had no resolution of swollen joints at 1 year. About half of these patient had consistently inflamed joints over time. Another third of the PsA patients had intermittently inflamed joints. At baseline these groups seems comparable in clinical presentation, demographics and PROMs, although some variation existed between early versus never and early versus intermittent resolution of swollen joints. Both indices provide room for improvement in the management of oligoarticular disease in PsA.

References:

[1] Wervers K et al. 2018 Nov;45(11):1526-1531

[2] Jones SM, et al. Br J Rheumatol. 1994;33(9):834-9

[3] Dönmez S, et al Clin Rheumatol. 2015;34(6):1091-6

[4] lannone F, et al Scand J Rheumatol. 2015;44(3):192-9

[5] Kruithof E, et al Arthritis Res Ther. 2005;7(3):R569-80

Disclosure of Interests: Marijn Vis Grant/research support from: Novartis, Pfizer - grant/research support, Consultant of: AbbVie, Celgene Corporation, Eli Lilly, Novartis, Pfizer - consultant, Kok Marc Grant/research support from: Novartis, Pfizer, Celgene, Lilly, UCB, Consultant of: Novartis, Celgene, Speakers bureau: Celgene, Ilja Tchetverikov: None declared, Johanna Hazes: None declared, Jolanda Luime: None declared

DOI: 10.1136/annrheumdis-2020-eular.5850

\section{SAT0443 CONCOMITANT PSORIATIC ARTHRITIS AND INFLAMMATORY BOWEL DISEASE IN THE PSA BIOLOGICAL REGISTRY: HUR-BIO REAL LIFE RESULTS}

G. K. Yardımcı ${ }^{1}$, B. Farisoğulları ${ }^{1}$, B. Armagann ${ }^{1}$, E. Bilgin ${ }^{1}$, E. C. Bolek ${ }^{1}$, E. Duran ${ }^{1}$, L. Kılıç ${ }^{1}$, O. Karadag', A. Akdoğann ${ }^{1}$, Ş. A. Bilgen ${ }^{1}$, A. İ. Ertenli', S. Kiraz ${ }^{1}$, U. Kalyoncu ${ }^{1} .{ }^{1}$ Faculty of Medicine; Hacettepe University, Rheumatology, Ankara, Turkey

Background: Patients with spondyloarthritis (SpA) have 3 important extra-articular involvement; psoriasis, uveitis and inflammatory bowel disease (IBD). Psoriatic arthritis (PSA) patients may have IBD, as well, and clinical features of PSA + IBD patients do not assess comprehensively, yet.

Objectives: The purpose of this study is to determine the frequency and clinical features of concomitant PSA and IBD in a PsA biological DMARD cohort.

Methods: Hacettepe University Rheumatology Biologic (HUR-BIO) is a single center biologic registry since 2005 and include 469 psoriatic arthritis patients to date. Demographics, clinical features, co-morbidities, laboratory and disease activity parameters collected from the database. The diagnosis of IBD was accepted with colonoscopy findings and pathology.

Results: Overall, 469 PsA patients (70\% females) with the mean age $47.7 \pm 12.4$ years and [median (IQR)] disease duration 7 (3-11) years included in the study. Overall, $10 / 469$ (5 male) PsA patients $(2.1 \%)$ had IBD $(7(70 \%)$ with ulcerative colitis and $3(30 \%)$ Crohn's disease). Mean age of the patients was $53.3 \pm 10.0$ years and mean disease duration was $9.0 \pm 6.1$ years. Six of ten patients were diagnosed with IBD before PsA and 4 of them were diagnosed with PsA first. Patients were followed-up for $3.7 \pm 2.8$ years and bDMARD switch were made in 4 patients mostly due to primary inefficacy. bDMARD was discontinued in 2 patients (one for Crohn disease with fistula and one for drug induced SLE). According to DAPSA score $44 \%$ of the patients had low disease activity and $56 \%$ of the patients had moderate disease activity at last visit ( 9 patients were available). Sacroiliitis (70\%) and severe radiographic hip (20\%) involvement were common in PsA patients with IBD. Disease characteristics and demographic data are given in table 1 .

Table 1. Disease characteristics and demographic data of PsA patients with IBD

\begin{tabular}{|c|c|c|c|c|}
\hline $\begin{array}{l}\text { Age (years) } \\
\text { /sex }\end{array}$ & $\begin{array}{l}\text { Disease dura- } \\
\text { tion (years) }\end{array}$ & IBD type & Sacroiliitis & Last visit treatments \\
\hline $61 / \mathrm{M}$ & 16 & Crohn's disease & $(+)$ & Azathioprine, GC \\
\hline 50/M & 5 & Ulcerative colitis & $(+)$, hip & Adalimumab, GC \\
\hline $59 / F$ & 3 & Ulcerative colitis & $(+)$ & Certolizumab, methotrexate \\
\hline $40 / F$ & 10 & Ulcerative colitis & $\because$ & Adalimumab, methotrexate \\
\hline 71/M & 19 & Ulcerative colitis & - & Infliximab \\
\hline $62 / \mathrm{M}$ & 13 & Crohn's disease & (+), hip & $\begin{array}{l}\text { Azathioprine, GC, } \\
\text { sulphasalazine }\end{array}$ \\
\hline $50 / F$ & 1 & Ulcerative colitis & - & Adalimumab, GC \\
\hline $59 / \mathrm{M}$ & 12 & Crohn's disease & $(+)$ & Secukinumab, GC \\
\hline $45 / F$ & 9 & Ulcerative colitis & $(+)$ & Adalimumab, methotrexate, GC \\
\hline $36 / F$ & 5 & Ulcerative colitis & $(+)$ & Infliximab, methotrexate, GC \\
\hline
\end{tabular}

Conclusion: In our single center biological registry, relatively small portion of PsA patients had concomitant IBD, however, those cases may have severe axial involvement, particularly in hip involvement, and further studies needed for these subgroup. Physician should be aware those SpA subgroup, because treatment choices, particularly IL-17 inhibitors may have some cautions patients with PsA and IBD.

Disclosure of Interests: Gözde Kübra Yardımcı: None declared, Bayram Farisoğulları: None declared, Berkan Armagan: None declared, Emre Bilgin: None declared, Ertugrul Cagri Bolek: None declared, Emine Duran: None declared, 